\title{
CONGENITAL GENU RECURVATUM WITH DISLOCATION OF KNEE: A CASE REPORT
}

Kalawar Rosan Prasad Shah, Chaudhary Shipra, Kalam Abul, Sitoula

Prakash, Jha Ranjiv and Shah Sanjaya

\begin{abstract}
:
A baby girl was born with severe deformity of left knee. Clinically and radiologically she was diagnosed as congenital dislocation of left knee. Gentle manipulation followed by above knee POP slab corrected the deformity in three weeks. A follow up at the age of 6 months showed normal position and range of motion of the knee. We are reporting this case for its rarity. Early recognition requires simple intervention only.
\end{abstract}

Key words: congenital genu recurvatum, knee dislocation, hyperextension of knee

\section{Introduction:}

Congenital genu recurvatum is a rare malformation characterized by hyperextension of the knee and marked limitation of flexion ${ }^{1}$. We report a case of a newborn baby with hyperextension of both knee joints and anterior dislocation of tibia on femur.

\section{Case report}

A full term baby girl born by normal vaginal delivery, presented with extreme hyperextension of left knee (fig.1a). Both knees were straightened passively. There
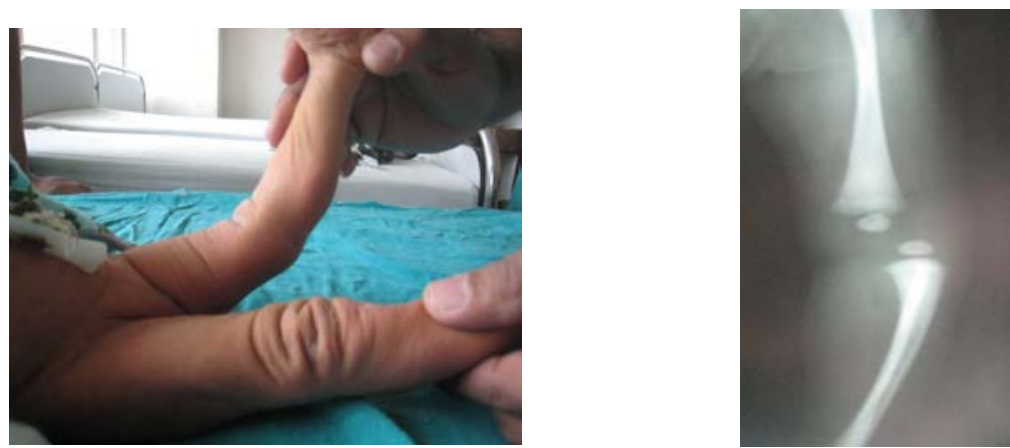

Fig.1a. Congenital genu recurvatum of left knee; Fig.1b. radiograph of the knee 


\section{Discussion:}

Congenital genu recurvatum is an uncommon condition that can present in three different forms, namely, congenital hyperextension, congenital hyperextension with anterior subluxation of the tibia on the femur, and congenital hyperextension with anterior dislocation of the knee joint on the tibia (fig.2). Hyperextension is frequently present in normal knees of a breech baby ${ }^{2}$.
The position in utero may influence the development of dislocation of the knees when the fetus is in breech position. Congenital dislocation of the knee, first described in 1922, is a rare condition, and is sometimes associated with other congenital malformations ${ }^{3,4}$. Diagnosis is made by physical findings of hyperextension and anterior displacement of the tibia. A radiograph confirms the diagnosis of dislocation

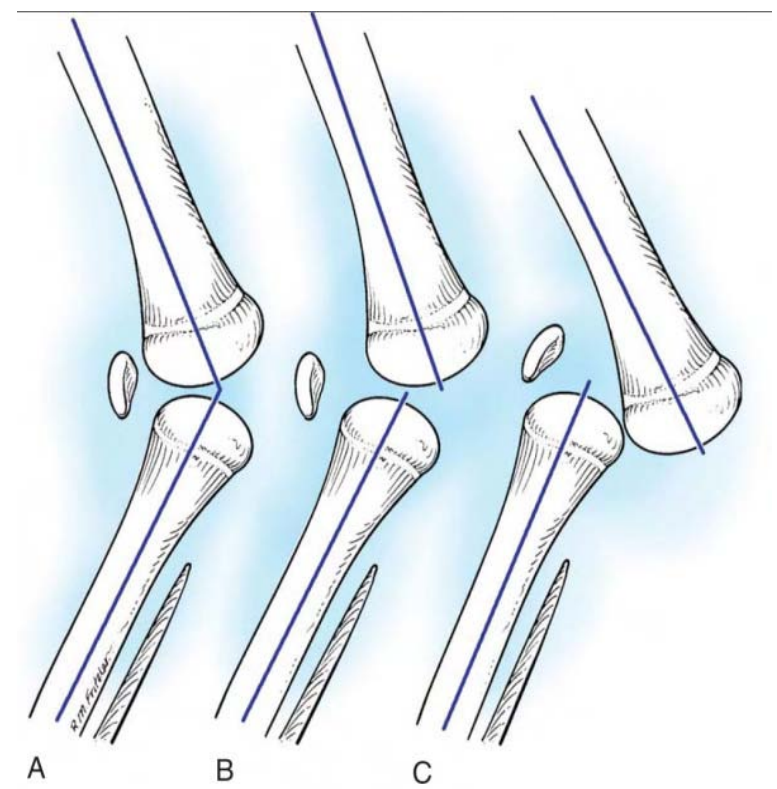

1. Fig.2. A, congenital hyperextension B, congenital subluxation $\mathrm{C}$, congenital dislocation of knee (extraced from: Canale ST, Beaty JH. Campbell's Operative Orthopaedics, 11th ed, volume II)

The treatment depends on the severity of the dislocation and the age of the patient. We agree with the other authors that nonoperative treatment is usually successful, if commenced at birth. Early manipulation, combined with splinting and casting is the mainstay of treatment in dislocation. Late presentation may require surgical release of the anterior structures of $\mathrm{knee}^{3,4}$. We achieved full correction within a short period of time. The key to success was early gentle manipulation and reduction followed by above knee POP slab. Emphasis should be laid on the immediate recognition and treatment of the condition.

\section{References:}

1. Fernandez PF and Silva JR. Congenital dislocation of the knee. Int Orthop 1990; 14:17-19.

2. Reach JW and Richard BS. Instructional Case: Congenital Dislocation of the knee. J Paediatr Orthop 1988; 8:226. 
3. Curtis BH, Fischer RL. Congenital hyperextension and anterior subluxation of the knee: Surgical treatment \& long term observation. J Bone Joint Surg (Am) 1969; $51: 255-269$
4. Muhammad KS, Koman LA, Mooney JF and Smith BP. Congenital dislocation of the knee: overview of management options. J South Orthop Assoc 1999; 8:9397.

Rosan Prasad Shah Kalawar, Prakash Sitoula, Ranjiv Jha and Sanjaya Shah, Lecturers at the Department of Orthopedics, Nobel Medical College, Biratnagar. Abul Kalam, Assistant Professor, Department of Orthopedics, Nobel Medical College, Biratnagar. Shipra Chaudhary, Resident, Department of Pediatrics, B. P. Koirala Institute of Health Sciences, Dharan. Address for Correspondence: Dr Rosan Pd Shah Kalawar, Nobel Medical College and Research Center, Biratnagar, Nepal. Mobile no: +977-9852049586; E-Mail: docrosan@yahoo.com. 